\title{
EDUCAÇÃO FÍSICA E FORMAÇÃO HUMANA OMNILATERAL: LIMITES E POSSIBILIDADES DA ABORDAGEM CRÍTICO-SUPERADORA
}

\author{
EDUCACIÓN FÍSICA Y FORMACIÓN HUMANA OMNILATERAL: LÍMITES Y \\ POSIBILIDADES DEL ENFOQUE CRÍTICO DE SUPERACIÓN
}

\section{PHYSICAL EDUCATION AND OMNILATERAL HUMAN FORMATION: LIMITS AND POSSIBILITIES OF THE CRITICAL APPROACH}

DOI: http://dx.doi.org/10.9771/gmed.v12i1.34163

\author{
Zuleyka da Silva Duarte ${ }^{1}$ \\ Vagner Augusto de Oliveira Schmidt ${ }^{2}$ \\ Avelino da Rosa Oliveira ${ }^{3}$
}

\begin{abstract}
Resumo: O presente estudo traz para o debate o tema da Formação Humana Omnilateral, articulado às proposições teóricas da Educação Física Escolar e tem como objetivo analisar a abordagem teórica CríticoSuperadora, com a intenção de propor aprofundamentos que a conduzam como referência de uma proposta de Formação Humana Omnilateral. Destarte, reafirmamos a necessidade de ampliar o escopo conceitual, contemplando os aspectos biofísicos do processo de formação humana, bem como inserir os elementos teórico-metodológicos no ensino dos conteúdos da cultura corporal, a partir da Praxiologia Motriz e dos conceitos de lógica interna e externa.
\end{abstract}

Palavras-chave: Abordagem Crítico-Superadora, Formação Humana Omnilateral, Praxiologia Motriz

Abstract: The present study brings to the debate the theme of Omnilateral Human Formation, articulated with the theoretical propositions of Physical Education and aims to analyze the Critical-Overcoming theoretical approach, with the intention of proposing further studies that will lead to it as a reference of a Formation proposal. Omnilateral Human. Thus, we reaffirm the need to broaden the conceptual scope, contemplating the biophysical aspects of the process of human formation, as well as inserting the theoretical-methodological elements in the teaching of body culture contents, from the Motive Praxiology and the concepts of internal and external logic.

Key words: School Physical Education, Critical-Overcoming Perspective, Omnilateral Human Formation, Driving Praxiology.

Resumen: El presente estudio trae al debate el tema de la Formación Humana Omnilateral, articulada con las proposiciones teóricas de la Educación Física y tiene como objetivo analizar el enfoque teórico de la Superación Crítica, con la intención de proponer estudios adicionales que lo conducirán como referencia de una propuesta de Formación. Omnilateral Humano. Así, reafirmamos la necesidad de ampliar el alcance conceptual, contemplando los aspectos biofísicos del proceso de formación humana, así como insertando los elementos teórico-metodológicos en la enseñanza de los contenidos de la cultura corporal, desde la Praxiología Motiva y los conceptos de lógica interna y externa.

Palabras-clave: Educación Física escolar, Enfoque Crítico-Superador, Formación Humana Omnilateral, Praxiología Motriz.

\section{Introdução}


O presente estudo insere-se no campo das Teorias Críticas da Educação em articulação com as Teorias da Educação Física e desenvolve-se como uma reflexão filosófico-educacional à luz da Filosofia Social Marxiana. Traz para o debate o tema da Formação Humana Omnilateral, vinculado ao que poderia se considerar uma pedagogia marxiana, dado o vigor com que Marx trata os temas da educação no conjunto de sua obra. A rigor, pode-se afirmar que a temática da Formação Omnilateral se refere à própria asserção da emancipação humana e à intrínseca relação educação/trabalho nesse processo. Neste constructo, entretanto, limitamo-nos a versar sobre as correlações existentes entre Educação Física, enquanto um componente pedagógico e Formação Omnilateral na perspectiva da educação e cultura corporal.

Considerando, portanto, o que o sistema do capital nos oferece como proposta de formação - que privilegia apenas um aspecto das capacidades humanas - e, sabendo que Marx expressa como projeto formativo uma educação que contemple o ser humano em todas as suas potencialidades, contrapondo-se, portanto, ao sistema do capital, justificamos a necessidade de propor o debate sobre a Formação Humana Omnilateral, como alternativa para uma educação emancipatória.

Sabendo que a omnilateralidade busca o desenvolvimento pleno dos indivíduos em todas as suas dimensões, dessarte a instituir-se como ser genérico; considerando que tais dimensões constituem-se na esfera das relações produtivas, sociais e subjetivas; compreendendo o corpo como uma das lateralidades do humano; considerando ainda o arcabouço teórico de que dispõe a Educação Física escolar, para fundamentar diferentes propostas de Formação Humana, desenvolvemos na presente reflexão a assertiva de que a produção teórica do campo da Educação Física crítica, através da abordagem Crítico-Superadora, é indispensável para construir um projeto de Formação Humana Omnilateral em sua perspectiva corporal.

No entanto, compreendendo este trabalho como um fluxo próprio do processo de emancipação, na medida em que se constitui como uma autorreflexão, cuja intenção é privilegiar a omnilateralidade sob o prisma da educação corporal, nossa argumentação buscará expor os limites da Educação Física escolar, na perspectiva de mediar um projeto de alcance omnilateral. Sem deixar de reconhecer que, no que ser refere a sua produção, a abordagem teórica mais bem elaborada para esse propósito é a Crítico-Superadora, pretendemos evidenciar, no entanto, a necessidade de alguns aprofundamentos, a fim de que seja capaz de melhor inserir-se na perspectiva da formação omnilateral. E na esteira desse pensamento, vimos propor uma articulação teórica com a teoria da Ação Motriz, ou Praxiologia Motriz, como possibilidade de pensar a lógica externa e interna das práticas corporais. Dito de outro modo, entendemos que a abordagem Crítico-Superadora pode dar novos passos em direção à formação humana omnilateral e, para tanto, nossa argumentação tem o objetivo de propor : 1) a reformulação do seu conceito de currículo; 2) a ampliação dos conteúdos da cultura corporal a serem tratados nos ciclos de escolarização, dando a mesma ênfase tanto ao processo analítico e de desenvolvimento do pensamento e da elevação intelectual dos estudantes, quanto ao processo de experimentação das práticas corporais e ao desenvolvimento biofísico dos 
sujeitos; 3) o diálogo com outras áreas do conhecimento e com outras escolas de pensamento, que estejam vinculadas a uma teoria crítica e que tenham desenvolvido temas contemporâneos pouco explorados por Marx no desenvolvimento do seu pensamento teórico; 4) articular a fundamentação teórico-metodológica da Abordagem Crítico-Superadora com as teorias da Praxiologia Motriz, a fim de dar conta da lógica externa, tanto quanto da lógica interna no processo ensino-aprendizagem dos conteúdos da cultura corporal.

\section{Pressupostos para uma pedagogia marxiana e a formação humana omnilateral}

A filosofia tem-nos mostrado, sob diversos aspectos, em diálogo com as diferentes ciências, que o homem, enquanto ser histórico, não nasce homem, mas torna-se homem. E o que o faz obter as características de um ser genérico são as múltiplas experiências, noções e habilidades que vai adquirindo, "não dadas a priori pela natureza, mas fruto do exercício que se desenvolve nas relações sociais, graças as quais o homem chega a executar atos, tanto 'humanos' quanto 'não naturais', como o falar e o trabalhar segundo um plano e um objetivo" (MANACORDA, 2010, p. 26).

Nesse sentido, cabe ressaltar a importância da educação e dos processos formativos, que medeiam a existência e, de certa forma, preparam as sucessivas gerações para viver em sociedade. Houve, portanto, a necessidade de se criar espaços específicos onde seja possível trabalhar as múltiplas capacidades do ser humano na perspectiva da historicidade, da transitoriedade de toda e qualquer formação existente, e “(...) também da sua arbitrariedade em relação a racionalidade humana na medida em que nenhum resultado orgânico da sua história foi, até agora, desejado e planejado pelo homem" Manacorda (2010, p. 27).

Há expresso, no pensamento de Manacorda (2010), uma constatação que deve ser levada à cabo: a explícita relação que esse modelo de educação propõe com a conservação do modo de produção capitalista, na medida em que, na maioria das vezes, não consideramos as instituições educativas como estruturas historicamente determinadas, mas a tratamos como naturais, imutáveis e eternas. O autor argumenta, exemplificando ainda a relação fábrica versus escola: a tecnologia transforma a fábrica, mas não o faz em relação a escola (ainda que disponha de novos conteúdos e instrumentos), pois enquanto a fábrica (sem levar em consideração alguns processos de trabalho ditos "naturais" e já problematizados por Marx) "não pode assemelhar-se a si mesma e a sociedade da qual faz parte" (p. 28), a nossa estrutura educativa parece mais, segundo o autor, a "escola do mundo helenístico - romano", ou, no máximo, "àquela dos humanistas ou dos jesuítas e está escassamente articulada à sociedade que atua" (p. 28).

Para Manacorda (2010) a educação e a escola estão anacrônicas. O modelo de educação vigente não contempla o objetivo de desenvolver os sujeitos em todas as suas dimensões de modo que, a formação das novas gerações fica comprometida com um ensino parcial e que favorece à reprodução das contradições sociais. Apesar disso, enquanto espaço plural, dialógico e de produção 
do conhecimento, compreendemos que a escola possui um potencial transformador, haja vista que é um espaço aberto às classes populares, onde pode-se projetar uma nova sociedade.

Em um trabalho de trinta anos, nasce uma doutrina absolutamente consistente, cuja perspectiva aponta para a emancipação humana e da sociedade. Essa doutrina apresenta, no bojo de sua filosofia social, a omnilateralidade como princípio de formação humana, apontando justamente a emancipação humana como o caminho a ser perseguido. Oliveira e Oliveira (2014, p. 217), afirmam:

O princípio da formação omnilateral encontra seus fundamentos numa concepção antropológica que põe, frente a frente, de um lado, o estatuto humano sob a lógica do capital e da propriedade privada, e, do outro, seu vir-a-ser, portanto, sua formação, com superação de tal modelo de sociabilidade.

O advento da industrialização introduziu, nos processos de trabalho, a separação sistemática do trabalhador com o produto do seu trabalho, de modo que a arte e as ciências se separaram no processo de produção e as formas de conhecimento, de modo geral, passaram a ser propriedade do capital.

Segundo Dangeville (1978, p. 15), o capital opera em uma dupla frustração das massas:

Em primeiro lugar, o corpo especializado de pensadores, de artistas e de professores - esses últimos que transmitem o saber de geração em geração, para 'reproduzir', conservando-o e perpetuando-o - tira o que há de melhor no saber e na sensibilidade que emana das massas, enquanto elas próprias permanecem incultas. Em seguida, por intermédio do mercado - que não é como desejava Estaline, troca neutra, mas troca com lucro, roubo, pilhagem e espoliação - as massas ficam desprovidas dos frutos de seus esforços.

Como contraponto à concepção burguesa de educação (abstrata, idealista, erudita, enciclopédica), está a plena formação do indivíduo, expressa em um documento de fundamental importância para a compreensão da proposta educativa de Marx, diz respeito às Instruções aos Delegados. Neste documento, Marx e Engels referem-se mais especificamente ao conteúdo da educação comunista e à atenção que deve ser dada à criança desde os nove anos, quando inicia sua inserção no mundo do trabalho e aponta o conteúdo indispensável ao ensino socialista:

Por ensino entendemos três coisas: Primeira: ensino intelectual. Segunda: Educação Física dada nas escolas através de exercícios militares (grifo meu); Terceira: adestramento tecnológico que transmita os fundamentos científicos gerais de todo o processo de produção e que, ao mesmo tempo, introduza a criança e ao adolescente no uso prático e na capacidade de manejar os instrumentos elementares de todos os ofícios. Com a divisão das crianças e dos adolescentes dos nove aos dezessete anos em três classes, deveria estar vinculado um programa de ensino intelectual, físico e tecnológico... A união do trabalho produtivo remunerado, ensino intelectual, exercício físico (grifo meu) e adestramento politécnico elevarão a classe operária acima das classes superiores e mediais (MARX \& ENGELS, 1962, apud MANACORDA, 2010, p. 48).

Evidencia-se, portanto, a necessidade de abrangência omnilateral de todos os fundamentos científicos da produção, enfatizando os três aspectos indispensáveis à formação humana: intelectual, físico e politécnico, em que um não substitui o outro.

$\mathrm{Na}$ sequência da argumentação e, corroborando com a concepção de omnilaterilidade exposta na Filosofia Social Marxiana, buscamos analisar as contribuições da Educação Física Escolar, 
para fundamentar uma proposta com essa envergadura, tendo como referência a educação corporal como uma das lateralidades a ser desenvolvida.

\section{As contribuições da educação física escolar para uma formação omnilateral}

\section{Limites}

Reafirmando que temos como pressupostos, primeiro, que nosso campo de interesse é a Educação Física escolar, a qual defendemos ser, dentre inúmeras outras possibilidades pedagógicas, uma área do conhecimento que pode contribuir de modo significativo para a proposta de Formação Humana Omnilateral e, segundo, que consideramos a abordagem Crítico-Superadora a mais bem elaborada nesse sentido, buscamos, de maneira mais rigorosa, aprofundar alguns aspectos que consideramos importantes para o seu aprimoramento.

A fim de dar conta de tal fito, é necessário proceder-se a uma análise um tanto detida da obra que compõe o arcabouço teórico da mencionada abordagem, qual seja, Metodologia do Ensino da Educação Física, publicada inicialmente no ano de 1991 e revista e reeditada no ano de 2012, ambos pela Editora Cortez. Esse trabalho é um clássico do campo teórico da Educação Física escolar, organizado e construído pelo autodenominado Coletivo de Autores: Lino Castellani Filho, Carmen Lúcia Soares, Celi Nelza Zülke Taffarel, Elizabeth Varjal, Micheli Ortega Escobar e Valter Bracht.

Publicada em um momento histórico de intensos questionamentos acerca da identidade da Educação Física escolar e com uma proposta de ruptura em relação à visão hegemônica técnicobiológico-higienista, que fundamentava o trabalho pedagógico até então, a abordagem CríticoSuperadora vincula seu objeto de estudo às Ciências Humanas e às teorias críticas da educação, a fim de desenvolver sua proposta teórico-metodológica de ensino da Educação Física escolar em contraposição às teorias de vertente cartesiana. Com isso, os autores buscam confrontar a fragmentação, a estaticidade, a unilateralidade, a terminalidade, a linearidade e o etapismo - princípios da lógica formal - com a totalidade, o movimento, a mudança qualitativa e a contradição, que informam os princípios curriculares abordados a partir da lógica dialética.

Dirigindo-se a aspectos um pouco mais particulares, os autores propõem os ciclos de escolarização, baseados no desenvolvimento cognitivo do aluno, e constroem o conceito de cultura corporal, confrontando-o com a perspectiva da aptidão física. Ainda outro ponto importante a mencionar é a concepção de currículo ampliado, desenvolvida pelo Coletivo de Autores e organizada a partir do resultado de estudos sobre o mesmo tema desenvolvidos pela Secretaria de Educação, Cultura e Esportes de Pernambuco, no período de março de 1987 a março de 1991. Em contraposição às conceituações tradicionais, a noção etimológica de currículo enquanto "corrida, caminhada, percurso" indica para os autores uma primeira aproximação conceitual que pode ser mais produtiva, na medida em que "o currículo escolar representaria o percurso do homem no seu processo de apreensão do conhecimento científico selecionado pela escola: seu projeto de 
escolarização." (Coletivo de Autores, 2009, p. 28-29). Com base nesse "projeto de escolarização", a função social do currículo é proporcionar a organização e ordenamento do conteúdo da reflexão pedagógica, imprimindo-lhe um desenvolvimento lógico. Assim, o aluno “apropria-se do conhecimento científico, confrontando-o com o saber que (...) traz do seu cotidiano e de outras referências do pensamento humano: a ideologia, as atividades dos alunos, as relações sociais, entre outros." (Coletivo de Autores, 2009, p. 29).

Sob outro ponto de vista, os autores afirmam que o "objeto do currículo é a reflexão do aluno” (p. 29). Para tanto, a escola não desenvolve o conhecimento científico, mas dele se apropria, conferindo-lhe um trato metodológico, de modo a facilitar sua apreensão pelo aluno. Nesse processo, a amplitude e a qualidade da reflexão são determinadas pela natureza do conhecimento selecionado e apresentado pela escola, bem como pela perspectiva epistemológica, filosófica e ideológica adotada. O que ordena essa amplitude é o que os autores consideram como eixo curricular: "princípio norteador e referência básica do currículo que está diretamente vinculado aos seus fundamentos sociológicos, filosóficos, antropológicos, psicológicos e biológicos” (p. 29).

As observações que faremos dizem respeito a um projeto de formação que busca, antes e acima de tudo, a formação plena do ser humano. Nesse sentido, entendemos que a concepção de currículo desenvolvida pelo grupo de autores enfatiza exacerbadamente uma única dimensão do ser humano, qual seja, o desenvolvimento da sua capacidade intelectual. Que essa lateralidade deva ser cultivada, concordamos integralmente com a proposta do Coletivo de Autores. No entanto, para contemplar o ser social na totalidade de suas dimensões, pensamos que o objeto do currículo não pode/deve fixar-se apenas - ou prioritariamente - no desenvolvimento da reflexão do aluno, mas propor a mesma ênfase na promoção de todas as suas capacidades. Assim, para mantermos a mesma linha de pensamento dos autores, julgamos necessário ampliar a noção de currículo, indo além do "percurso destinado a ordenar a reflexão do aluno". Se queremos seguir um caminho que nos aproxime da omnilateralidade, será imperioso, desde já, organizar o desenvolvimento do aluno em todas as suas dimensões, quais sejam: intelectual, espiritual, ética, estética, corporal etc. É preciso levar em consideração as diferentes maneiras de apreensão do real e que a abstração é apenas uma delas. A título de exemplificação, poderíamos lembrar a Declaração de Salamanca e o compromisso de a escola integrar pessoas com diferentes tipos de deficiência, inclusive a intelectual, o que não significa, entretanto, que outras capacidades do indivíduo não possam ser desenvolvidas. Elevar a capacidade intelectual dos alunos é um objetivo inerente à escola, mas que deve estar colocado com o mesmo grau de prioridade de outras capacidades que os indivíduos possam ampliar e requintar.

Outro aspecto em que a abordagem Crítico-Superadora carece algum avanço é no que se refere aos conteúdos da cultura corporal. A fim de elaborar sua posição, o Coletivo de Autores parte da diferenciação entre as perspectivas da aptidão física e da cultura corporal. Ao confrontar os dois paradigmas, lembram que o desenvolvimento da aptidão física do homem tem contribuído, historicamente, para a defesa dos interesses da classe no poder, mantendo a estrutura da sociedade capitalista. E colocam-se do lado oposto, defendendo que a reflexão desencadeada pela ideia de 
cultura corporal "busca desenvolver uma reflexão pedagógica sobre o acervo de formas de representação do mundo que o homem tem produzido no decorrer da história, exteriorizadas pela expressão corporal." (Coletivo de autores, 2009, p.39). Entre essas formas de exteriorização da relação homem-mundo são colocados, por exemplo, os jogos, as danças, as lutas, os exercícios ginásticos, o esporte em geral, o malabarismo, o contorcionismo, a mímica etc. O que importa na visão do Coletivo de Autores (2009) é que essas exteriorizações são a "forma de representação simbólica de realidades vividas pelo homem, historicamente criadas e culturalmente desenvolvidas." (p.39)

No entanto, do mesmo modo que, enquanto humanos, vamos nos constituindo pelas relações que estabelecemos com a natureza, com os outros e com nossa subjetividade, também é importante lembrar que essa ação se dá através de movimentos e práticas corporais, que, ao fim e ao cabo, vão formar o que chamamos de cultura corporal. Assim, faz-se necessário destacar que essas práticas, desenvolvidas pela capacidade motora dos sujeitos, vão sofrendo alterações significativas, devido às características individuais, do ambiente e das tarefas que este desenvolve.

Os aspectos biofísicos dos sujeitos e a adaptação que vão sofrendo no decorrer da sua trajetória também são conteúdos relevantes e que devem estar no mesmo nível de importância das demais práticas corporais produzidas pelo homem. Além disso, é indispensável incluir a história do corpo como conteúdo a ser tratado. As futuras gerações devem aprender as diferentes concepções de corpo discutidas no contexto da história, da filosofia e, principalmente, da indústria corporal. Assim, terão as condições para problematizar e questionar padrões físicos/culturais/comportamentais propostos por diferentes setores como o mercado, a mídia e a religião. Saúde, qualidade de vida, o corpo no contexto social da mulher, do homossexual, do transexual, do negro, do índio, dos miseráveis devem contemplar os conteúdos da cultura corporal e ser objeto de análise e discussão na trajetória escolar das futuras gerações. Ao mesmo tempo, compreendemos que também é tarefa da Educação Física promover atividades que tenham como objetivo tanto o desenvolvimento cardiorrespiratório quanto muscular. Às vezes, a escola é o único espaço onde os alunos poderão adquirir o gosto por um estilo de vida saudável e incorporar os exercícios físicos na rotina, mesmo depois de concluir a trajetória escolar.

Pensamos ainda ser indispensável que a abordagem Crítico-Superadora passe a estabelecer um diálogo mais sistemático com outras áreas de conhecimento e com outros paradigmas teóricos. Trabalhar a favor de um projeto de alcance omnilateral equivale a colocar no horizonte a emancipação humana e a liberdade, como indispensáveis na faina educativa. Isso implica afirmar que pautamos nossas ações a favor da radical superação do sistema do capital e da construção coletiva de uma alternativa ao sistema que usurpa do povo suas condições mais básicas de existência. Para tanto, é preciso que se tenham as condições objetivas - econômicas, sociais e jurídicas - e as condições subjetivas - a capacitação e a qualificação da população.

No entanto, passaram-se quase 200 anos desde que Marx, ainda na juventude, começou a problematizar e questionar o trabalho e a liberdade na então incipiente sociedade capitalista. Seus 
escritos, com efeito, são fundamentais e contemporâneos para pensarmos os mesmos problemas ainda hoje e, pautados na mesma linha de pensamento, buscar soluções coletivas. No entanto, dadas as condições, contradições e transformações do próprio sistema capitalista, sabemos que temos um longo caminho a percorrer. Assim, consideramos importante para a compreensão do corpo, para além daquele que age e produz, também aquele que sofre e que é objeto de condicionamento, opressão, violência. Nesse sentido, trabalhar com a Educação Física e não acessar as diferentes concepções de corpo que fundamentaram a história da humanidade deixa lacunas para pensarmos as questões que estão colocadas na contemporaneidade: as diferenças de classe, raça, etnia, religião, sexo e gênero.

Dialogar com outros autores se torna fundamental para compreendermos determinadas posições, trazer para o contexto questões que Marx não tematizou na sua vasta produção teórica e, assim, ampliar a reflexão sobre o papel da Educação Física escolar. E nisso não há qualquer prejuízo e em nada anula os esforços a favor da emancipação humana.

\section{Possibilidades}

Como vimos, a Educação Física é um componente pedagógico previsto no currículo escolar e cuja prática, historicamente, tem sofrido alterações que acompanham as transformações políticas e sociais do nosso tempo. Se, em um primeiro momento, essa área do conhecimento era pensada a partir de propósitos profiláticos, morais e culturais, cujo foco centrava-se na manutenção da saúde e da aptidão física, hoje, percebemos que houve um descolamento teórico-científico e que a compreende a partir de outros paradigmas, como o sócio-histórico e o cultural, por exemplo.

Suchodolski (1974) lembra que, segundo o pensamento de Marx, o homem vive sempre colocado em situações de escolhas e, ainda que seja um produto das relações sociais, pode decidir a vincular-se a um caminho ultrapassado ou ajustar-se com novas possibilidades. Destarte, ele afirma: "Partindo de este critério, el aspecto essencial de la educación moral estriba em la participación del hombre em la lucha por el progresso histórico, llevado a cabo mancomunadamente con los demás indivíduos" (SUCHODOLSKI, 1974, p. 49).

Nessa linha de pensamento, analisando, especificamente a Educação Física, Pierre Parlebas (2003) é categórico ao afirmar sobre a dificuldade de se mudar um ponto de vista, no que se refere aos parâmetros científicos, historicamente, utilizados na área. Ao apresentar a Praxiologia Motriz, como uma alternativa a esse parâmetro da modernidade, o autor defende a seguinte assertiva:

'Después de su casa, lo más difícil de cambiar es su pensamento', afirma el refrán popular. Este adágio se confirma plenamente em el campo de la educación física, em el que parece inconcebible que pueda cambiarse el punto de vista sobre las actividades físicas, ya que durante tanto tempo se ha convivido com la ideia de que cuerpo y espírito pueden separarse, o que el corpo no es más que una dimensión meramente biológica o técnica de la vida (PARLEBAS, 2003, p. 7).

No entanto, para romper com esta dualidade histórica presente na área da Educação Física e "despues de muchos decênios, ha llegado el día en que los nuevos conociminetos han llevado ao 
hombre y la sociedad a modificar estas concepciones obsoletas" (Idem, p. 7) e, promover a necessária mudança de paradigmas, o autor anuncia a divulgação de sua proposta teórico-metodológica desenvolvida através por Francisco Largadera Otero e Pere Lavega Burgués e conhecida como Praxiologia Motriz:

É nesse sentido que defendemos a necessidade de olhar o corpo em suas múltiplas dimensões e que a abordagem Crítico-Superadora - analisada através das seguintes categorias: 1) Projeto Histórico, definido pela base filosófica, a partir da qual constrói sua teoria e que aponta para a transformação da sociedade; 2) As opções epistemológicas em que define o que é Educação Física e qual a função social da Educação Física escolar e 3) os objetivos propostos ao ensino da Educação Física - é a proposição teórica mais avançada e mais consistente, para fundamentar um projeto de formação omnilateral, aparece como a fundamentação mais elaborada no que se refere àquilo que Largadera e Lavega (2003), chamam de lógica externa, ou seja, a grosso modo, fala-se sobre os fatores externos (sócio-histórico-culturais) que interferem na produção e reprodução das práticas corporais como um conhecimento a ser desenvolvido (questões de classe, raça, etnia, gênero, por exemplo). Sendo assim, o modo como as futuras gerações irão apreender sobre os determinantes sociais que implicam nos conteúdos da Educação Física e, com isso, ampliar o seu olhar crítico sobre a organização social, está proposto da Abordagem Teórica Crtítico-Superadora. No entanto, para ampliar a compreensão da dinâmica da prática, sem que se retorne ao puro tecnicismo, a Praxiologia Motriz dispõe de conceitos de extrema relevância que podem ser pensados, juntamente com a referida abordagem teórica, em uma perspectiva omnilateral no ensino da Educação Física Escolar.

\section{Breves Considerações sobre a Praxiologia Motriz}

A Praxiologia Motriz se constitui como uma ciência que observa as ações provenientes dos jogos, esportes e demais práticas motrizes no campo da Educação Física, buscando extrair o conhecimento que permeia as diferentes manifestações da Cultura Corporal, através da compreensão da Lógica Interna, representada pelas Ações Motrizes. Cada prática motriz dispõe de uma organização própria que comporta certas constantes estruturais. Esta ordem que inclui a Lógica Interna de qualquer jogo, orienta as ações dos seus participantes, que apesar de poderem tomar decisões motrizes individuais, devem atuar nos limites da interação da prática motriz (Largadera e Lavega, 2003).

Sendo assim, o conjunto de preceitos, condições e relações que as regras do jogo estabelecem, recebe a denominação de Lógica Interna, ou seja, o modo peculiar como as relações do jogo esportivo está pré-determinada. Conforme Largadera e Lavega (2003), desvelar a Lógica Interna de cada situação motriz, possibilita uma análise prévia do sistema praxiológico, de forma que se possa escolher e programar situações motrizes condizentes aos interesses dos próprios jogadores.

É importante ressaltar que as características da Lógica Interna estão ligadas, diretamente, às regras do jogo esportivo. Ou seja, conforme Ribas (2005), a Lógica Interna é uma estrutura lógica 
composta pelo jogo ou esporte, pelos protagonistas e agentes ativos envolvidos e por suas regras, comportando as características importantes da prática motriz. Ou seja, a Lógica Interna refere-se às relações que o praticante estabelece com os seus companheiros e/ou oponente, com o espaço destinado à prática, os materiais necessários e disponíveis e o tempo de realização.

Para além da relação com as regras do jogo, a Lógica Interna também dispõe de outras ferramentas científicas de análise, o que permite um maior compromisso sobre as diferentes manifestações motrizes. Neste sentido, Parlebas (1988) desenvolveu o que conhecemos como "Sistema de Classificação CAI", que constitui a primeira aproximação para a compreensão de um jogo ou esporte e, a partir de critérios determinados, é possível conhecer qualquer característica de qualquer prática motriz.

Dessa forma, a fim de classificar as práticas motrizes conforme as características pertinentes a sua lógica interna, o Sistema de Classificação CAI é estruturado com base nas interações motrizes estabelecidas com companheiro (C), adversário (A) e com a incerteza do meio da prática (I). Para Largadera e Lavega (2003), a combinação desses três critérios - companheiro, adversário e ambiente - possibilita caracterizar qualquer tipo de situação motriz.

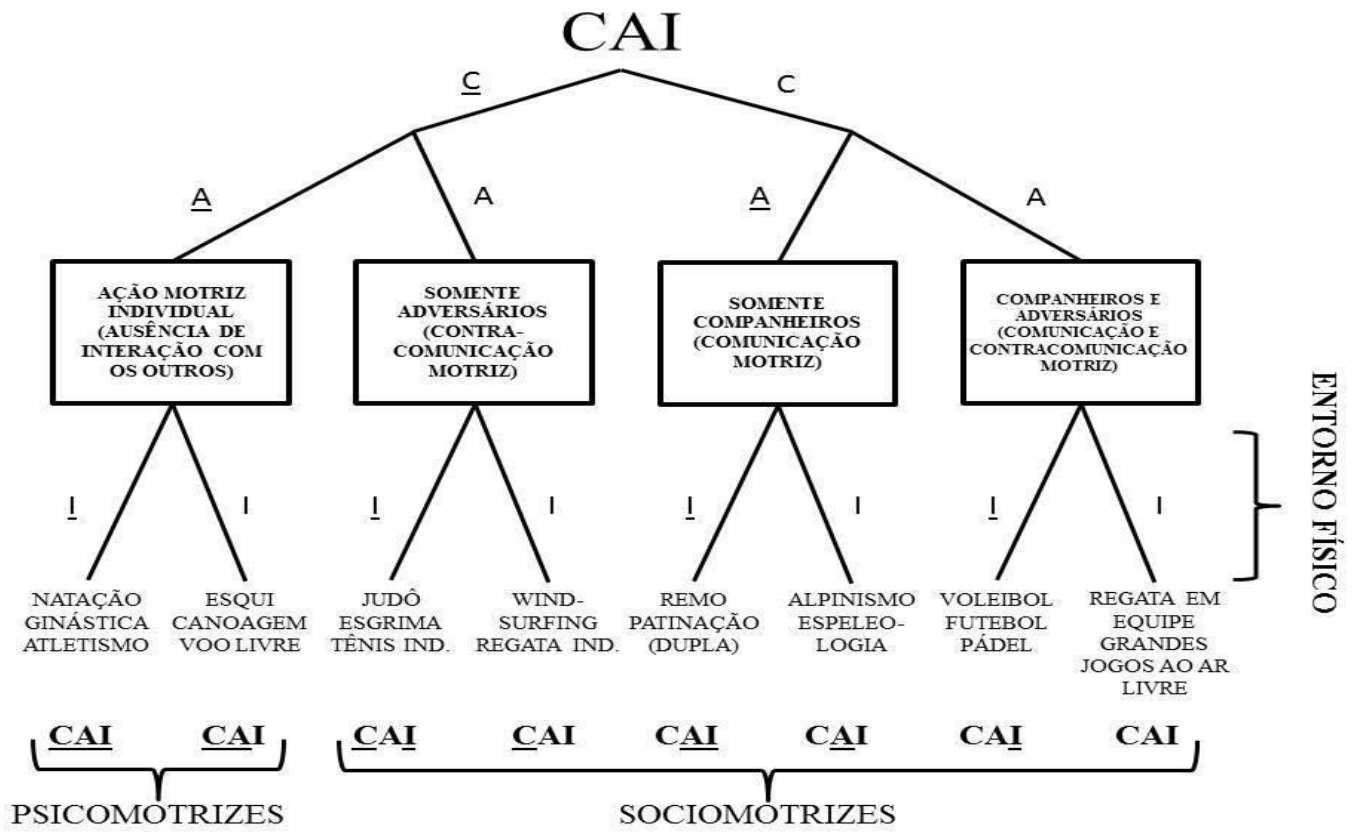

Figura 1: Sistema de Classificação CAI (Adaptada de Parlebas, 2001).

Dessa forma é possível classificar as práticas corporais como psicomotrizes - quando a interação motriz é individual (não há, portanto, interação com outros participantes) ou sociomotrizes - quando há interação de comunicação ou contracomunicação com outros participantes.

A análise da lógica interna de cada ação motriz promove a possibilidade de uma compreensão das consequências práxicas, que ocorre em todo sistema praxiológico, de modo que com isto, possa-se interpretar as ações motrizes do adversário e/ou companheiro e programar as respostas de acordo com os propósitos do participante no jogo. 
Evidentemente que para estes objetivos, os evolvidos nos jogos, esportes e/ou práticas corporais, tem de dispor de conhecimentos provenientes da Biologia, Fisiologia e Biomecânica, por exemplo. No entanto, conforme os próprios autores afirmam, a prática esportiva é levada à efeitos por "pessoas", o que pressupõe a existência de um contexto socio-histórico-cultural:

Esta é la razón que justifica la existencia de multitud de disciplinas interessadas em estudiar aspectos de este fenomeno, aspectos contextuales, su logica externa (grifo meu), fundamental para entender el fenomeno em su totalidade, pero los que intervienen diretamente en la practica necesitan conocer detenidamiente su patrón de organización, su logica interna (LARGADERA e LAVEGA, 2013, p. 68).

No caso da lógica externa, por exemplo, compreender o contexto em que o esporte está inserido e os aspectos socio-histórico-culturais que interferem na prática, são de extrema importância as contribuições da filosofia, psicologia, antropologia e sociologia, por exemplo.

É nesse sentido que compreendemos que, para avançar na ampliação da capacidade intelectual dos alunos, a partir dos conteúdos da cultura corporal, cuja reflexão pedagógica tem como eixo "a constatação, a interpretação, a compreensão e a explicação da realidade social complexa e contraditória", Coletivo de Autores (2009, p.30), fundamentada na filosofia social marxiana, bem como os conceitos desenvolvidos por Parlebas (1988) do Sistema de Classificação CAI e Lógica Interna é necessário uma articulação com referencial teórico-metodológico da Praxiologia Motriz, no sentido de avançar no que se refere a uma aproximação com as concepções de Educação Física com uma Formação Humana Omnilateral

\section{Considerações finais}

Uma das tarefas do sujeito em seu processo de emancipação, além do pensamento crítico, no que diz respeito às relações do homem consigo mesmo, com os outros e com modo como produz a existência e a resistência intransigente contra qualquer forma de opressão e exploração, é a autorreflexão. No momento em que buscamos, através das nossas ações, do nosso trabalho, um mundo melhor e mais justo, a todo momento, precisamos ver e rever onde estamos e aonde queremos chegar, e se o percurso que estamos traçando é o mais adequado.

É nesse sentido que buscar argumentos que justifiquem a Formação Humana Omnilateral como um dos processos de formação capazes de conduzir o homem à plenitude de todas as suas potencialidades e o papel da Educação Física escolar nesse decurso exige um olhar rigoroso para a disputa travada no âmbito da sociedade capitalista e que se explicita, de modo geral, nas teorias pedagógicas.

Destacamos que a proposições teórica que apresenta uma maior identificação com uma concepção de Formação Omnilateral, não só pela concepção de formação, mas também pela defesa de um projeto histórico transformador, que busca a superação do capitalismo, é a abordagem CríticoSuperadora. 
No entanto, ainda que o referencial teórico que compõe sua base filosófica seja resultante de uma concepção histórica e materialista da sociedade, encontramos alguns "limites", para que se possa pensá-la em uma perspectiva omnilateral.

Em linhas gerais, o pensamento desenvolvido pelos autores é o que representa de mais avançado no campo teórico da Educação Física escolar. Não obstante, para pensar a questão da omnilateralidade, destacamos um ponto, digamos, "nevrálgico" da referida abordagem: o destaque para a ampliação da capacidade intelectual do aluno em detrimento a um desenvolvimento de todas as potencialidades, até porque, a escola é formada por alunos com altas habilidades nos aspectos mais racionais do conhecimento humano e outros que se destacam pela capacidade estética e habilidades manuais, outros aspectos que também compõem os conteúdos da cultura corporal, bem como trabalhamos com alunos com deficiências cognitivas, intelectuais e/ou motoras. A ênfase na elevação intelectual está assinalada em várias passagens que constituem a proposição Crítico-Superadora e demonstra, de alguma maneira, que, ainda que não intencionalmente, a concepção reafirma a supremacia da habilidade intelectual diante de outras capacidades humanas.

Defendemos a proposta que, em uma perspectiva omnilateral, busca a formação do aluno em todas as suas potencialidades e, ainda que não defendamos o corpo como uma estrutura biológica que não pensa, mas sim é pensada, não podemos desconsiderar a sua dimensão biofísica, aquilo que nos faz "seres vivos" e que permite nossa experiência e nossa existência no mundo.

Entendemos que o objetivo da abordagem é contrapor-se às concepções ligadas ao rendimento e à aptidão física - que por muito tempo conduziram o trabalho docente na escola - e oferecer ao professor um olhar crítico e problematizador dos conteúdos da cultura corporal.

Sugerimos, então, uma proposta de formação, capaz de dar conta das múltiplas potencialidades do ser humano, inspirada em uma visão materialista e histórica da sociedade e que tem como pano de fundo a emancipação humana. Chamamos essa proposta de Formação Omnilateral. Sabendo que, na sociedade capitalista, por sua natureza expropriativa, que vive do lucro, é impossível, nesse contexto, o homem atingir a posse de todas as suas capacidades, encontramos, na obra de Marx e na Filosofia Social Marxiana, argumentos e fundamentos para pensar em uma proposta de educação articulada e comprometida com a transformação radical da sociedade.

Assim, se por um lado é importante superar os "preconceitos epistemológicos" para alargar o entendimento sobre as concepções de corpo tratadas com muita competência nas filosofias de Foucault e Nietzsche, por exemplo, teoricamente, de uma escola filosófica diferente do Materialismo Histórico e Dialético, mas não necessariamente antagônica já que ambos os filósofos trazem para o contexto social, uma compreensão de corpo não pensada por Marx mas que amplia, de modo significativo o nosso entendimento do modo como o corpo (social, das mulheres, homens, crianças, trans, negros, brancos, trabalhadores, presidiários, etc) é evidenciado de acordo com os interesses da lógica do capital, por outro lado, para compreender as práticas corporais a partir da seus pressupostos técnicos, táticos e biofísicos, sem cair no mero tecnicismo e aptidão física propomos os estudos da 
Praxiologia Motriz, como possibilidade de busca uma formação plena das futuras gerações, sob a ótica da Educação Física escolar.

\section{Referências}

COLETIVO DE AUTORES. Metodologia do Ensino da Educação Física. 2ed.rev.São Paulo: Cortez, 2009.

DANGEVILLE, Roger. Crítica da Educação e do Ensino: introdução e notas. Lisboa: Moraes Editores, 1978.

LARGadera E LAVEGA, P. Introducción a la Praxiología Motriz. Barcelona: Paidotribo, 2003.

MANACORDA, Mário. Marx e a Pedagogia Moderna. 2 ed. Campinas, SP: Ed. Alínea, 2010.

MARX, Karl. O Capital: Livro I. São Paulo: Boitempo, 2013.

MARX, Karl. Manifesto do Partido Comunista. $2^{\mathrm{a}}$ ed. São Paulo: Martins Claret, 2008.

OLIVEIRA, A; OLIVEIRA, N. Modelos de Formação Humana: paideia, Bildung, formação omnilateral. In: Percursos Hermenêuticos e Políticos. Ed. UPF; Porto Alegre: Ed. PUCRS; Caxias do Sul: Ed. UCS, 2014. p. 208-222.

PARLEBAS, P. Elementos de sociologia del deporte. Málaga: Coleccción Unisporte-Junta de Andalucia, 1988.

RIBAS, J. F. M. Praxiologia Motriz: construção de um novo olhar dos jogos e esportes na escola. Motriz, 11(2), 113-120, 2005.

RIBAS, J. F. M. Prólogo. In: Introducción a la Praxiología Motriz. Barcelona: Paidotribo, 2003.

SUCHODOLSKI, Bogdan. Fundamentos de Pedagogía Socialista. Barcelona: Editorial Laia, 1974.

TAFFAREL, Celi Nilza. Perspectivas Pedagógicas em Educação Física. In: Atividade Física: uma abordagem multidimensional. GUEDES, O.C. (Org.). João Pessoa: Ideia, 1997.

\footnotetext{
Notas:

1 Professora concursada do Estado do Rio Grande do Sul. Coordenadora pedagógica da Escola Estadual de Ensino Fundamental Gen. Gomes Carneiro (EJA), e do Colégio Estadual Tancredo Neves (anos iniciais) - Santa Maria, RS. Doutora em Educação pelo Programa de Pós-Graduação em Educação da Universidade Federal de Pelotas - linha de pesquisa Filosofia e História da Educação. Pesquisadora do grupo de Pesquisa Filosofia, Educação e Práxis Social, (FEPRÁXIS/UFPEL) - http://dgp.cnpq.br/dgp/espelhogrupo/26494 e Grupo de Estudos Leituras e Epistemológia em Educação Física (LEEDEF). CV: http://lattes.cnpq.br/197895076808642 Orcid: https://orcid.org/0000-00026573-3454 Email: zukadu@gmail.com

2 Mestrando do Programa de Pós-graduação em Educação Física - UFSM. Grupo de Estudos Praxiológicos http://dgp.cnpq.br/dgp/espelhogrupo/32700 CV: $\quad$ http://lattes.cnpq.br/7926845510822968 Orcid: https://orcid.org/0000-0001-6352-3069 Email: vagner.vet@hotmail.com

3 Professor titular da Universidade Federal de Pelotas. Doutorado em Educação pela Universidade Federal do Rio Grande do Sul (2002). Membro do Grupo Filosofia, Educação e Práxis Social (FEPráxiS) - UFPEL -

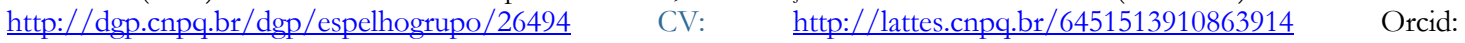
https://orcid.org/0000-0002-9567-5814 Email: avelino.oliveira@gmail.com
} 